\title{
Espaçamento entre plantas e cachos por haste no tutoramento vertical do tomateiro
}

Anderson Fernando Wamser; Siegfried Mueller; Walter F Becker; Janaína P dos Santos; Atsuo Suzuki EPAGRI-EE de Caçador, C. Postal 591, 89500-000 Caçador-SC; afwamser@epagri.sc.gov.br; simueller@epagri.sc.gov.br; wbecker@ epagri.sc.gov.br; janapereira@epagri.sc.gov.br; suzuki@epagri.sc.gov.br

\section{RESUMO}

O presente trabalho objetivou avaliar o efeito do espaçamento entre plantas e do número de cachos por haste sobre a produtividade e a qualidade de frutos do tomateiro conduzido no método de tutoramento vertical com fitilho. Experimentos foram conduzidos nas safras 2006/07 e 2007/08, na Epagri-Estação Experimental de Caçador-SC. Os tratamentos consistiram da combinação de três espaçamentos entre plantas $(30,45$ e $60 \mathrm{~cm})$, quatro alturas de desponta das plantas (sem desponta, cinco, sete e nove cachos por haste) e duas cultivares na safra 2006/07 (Débora Max e Nemo Netta) e uma cultivar na safra 2007/08 (Takii 92). Avaliou-se a produtividade de frutos total, comercial e descarte, a massa média de frutos comerciais e a porcentagem de frutos comerciais e descartados. Não houve interação entre os fatores cultivar, espaçamento entre plantas e níveis de desponta. A redução do espaçamento entre plantas de 60 para 45 $\mathrm{cm}$ aumentou de 15,2 a 17,2\% a produtividade de frutos comerciais, sem comprometer a qualidade. Não houve diferença entre altura de desponte para produtividade de frutos comerciais.

Palavras-chave: Solanum lycopersicum L., tutoramento de plantas, produtividade.

\begin{abstract}
Plant spacing and number of bunches per tomato stem vertically conducted

The effects of plant spacing and number of bunches per stem of tomato plants vertically conducted with polypropylene cord were evaluated on fruit yield and quality. Experiments were carried out during the 2006/2007 and 2007/2008 growing seasons, at EpagriCaçador Experimental Station, Santa Catarina State, Brazil. The treatments consisted of a combination of three plant spacing (30, 45 and $60 \mathrm{~cm}$ ), four topping heights (no topping, and topped at $5^{\text {th }}$, $7^{\text {th }}$ and $9^{\text {th }}$ bunch per stem) and the cultivars Débora Max and Nemo Netta in 2006/2007 and the cultivar Takii 92 in 2007/2008. Total, marketable and unmarketable yield, marketable mean weight, and the percentage of marketable and unmarketable fruits were evaluated. There was no significant interaction between cultivars, topping heights and plant spacing. Reduction in row plant spacing from 60 to $45 \mathrm{~cm}$ increased the marketable tomatoes from 15.2 to $17.2 \%$, without affecting the fruit quality. The number of bunches per stem did not affect marketable yield.
\end{abstract}

Keywords: Solanum lycopersicum L., plant staking, tomato yield.

(Recebido para publicação em 26 de janeiro de 2009; aceito em 4 de novembro de 2009) (Received in January 26, 2009; accepted in November 4, 2009)

$\mathrm{O}$ tutoramento vertical de plantas de tomate apresenta diversas vantagens em relação ao tutoramento cruzado ou "V" invertido. No método de tutoramento cruzado, a formação de um ambiente úmido e quente sob o "V" invertido é favorável ao desenvolvimento de fitopatógenos (Rebelo, 1993). Além disso, a aplicação de defensivos nos órgãos das plantas localizados no interior do " $\mathrm{V}$ " invertido é deficiente, dificultando o controle de pragas (Picanço et al., 1995) e doenças (Boff et al., 1992).

No método de tutoramento vertical do tomateiro, além da aplicação dos defensivos ser mais eficiente nos dois lados das plantas ao longo das filas (Picanço et al., 1995), há uma melhor distribuição da radiação solar e maior ventilação ao longo do dossel das plantas, reduzindo o período de molhamento foliar e a severidade das doenças (Santos et al. 1999;
Wamser et al., 2008) e aumentando a produtividade de frutos comerciais (Wamser et al., 2007).

A melhoria das condições fisiológicas e fitossanitárias das plantas com o tutoramento vertical pode permitir a diminuição do espaçamento entre plantas com o objetivo de incrementar a produtividade. Na região do Alto Vale do Rio do Peixe, SC, o espaçamento entre plantas comumente utilizado pelos produtores é de $60 \mathrm{~cm}$, com a condução de duas hastes por planta, observandose variações de 20 a $70 \mathrm{~cm}$, de acordo com a cultivar e o número de hastes por planta (Mueller et al., 2008).

Muitos produtores desta região que utilizam o método de tutoramento vertical de plantas estão reduzindo o espaçamento entre plantas para $50 \mathrm{~cm}$. Em vários trabalhos foram observados aumentos da produtividade de frutos com a redução do espaçamento entre plantas (Streck et al., 1998; Seleguini et al., 2006; Machado et al., 2007). Entretanto, o aumento da densidade de plantas reduz a massa média de fruto (Streck et al., 1998; Carvalho \& Tessarioli Neto, 2005; Machado et al., 2007). Este fenômeno acarreta o aumento da produtividade de frutos médios, em detrimento da produtividade de frutos graúdos (Seleguini et al., 2002), de maior valor comercial.

Geralmente, os frutos localizados nos cachos superiores possuem menor tamanho e, muitas vezes, não atingem o ponto de colheita por ocasião do final da safra (Streck et al., 1998). Na região do Alto Vale do Rio do Peixe, as plantas geralmente são conduzidas sem a realização da desponta e podem alcançar mais de 20 cachos por planta. A desponta é uma prática na qual se remove a gema apical das hastes. Isto limita o número de cachos por haste e permite o aumento do 
tamanho dos frutos remanescentes (Machado et al., 2007), principalmente nos cachos situados no terço superior das plantas (Pereira et al., 1999). Assim, a diminuição do espaçamento entre plantas no método de tutoramento vertical, aliada ao uso da desponta, poderá promover o aumento na produtividade sem comprometer a qualidade dos frutos.

O presente trabalho teve como objetivo avaliar o efeito do espaçamento entre plantas e do número de cachos por haste sobre a produtividade e a qualidade de frutos do tomateiro conduzido em tutoramento vertical com fitilho.

\section{MATERIAL E MÉTODOS}

Os experimentos foram conduzidos durante as safras 2006/07 e 2007/08, na Epagri-Estação Experimental de Caçador, em Caçador-SC, na região fisiográfica do Alto Vale do Rio do Peixe. Os solos nos locais dos experimentos foram classificados como Latossolo Bruno distrófico típico (Embrapa, 1999) e apresentaram os seguintes atributos: $\mathrm{pH}($ água $)=5,7$ e 6,$1 ; \mathrm{P}=6,0$ e $3,6 \mathrm{mg}$ $\mathrm{L}^{-1} ; \mathrm{K}=210$ e $106 \mathrm{mg} \mathrm{L}^{-1} ; \mathrm{MO}=45$ e 42 $\mathrm{mg} \mathrm{g}^{-1} ; \mathrm{Al}=0,0$ e $0,0 \mathrm{cmolc} \mathrm{L}^{-1} ; \mathrm{Ca}=11,2$ e 9,6 cmolc L L $^{-1} \mathrm{Mg}=4,6$ e 4,1 cmolc L c $^{-1}$; $\mathrm{V}=75$ e $80 \%$, para as safras 2006/07 e 2007/08, respectivamente.

Os tratamentos, na safra 2006/07, consistiram da combinação de duas cultivares (Débora Max e Nemo Netta), três espaçamentos entre plantas $(30,45 \mathrm{e}$ $60 \mathrm{~cm}$ ) e quatro alturas de desponta (sem desponta, cinco, sete e nove cachos por haste). $\mathrm{O}$ delineamento experimental foi blocos completos ao acaso, com quatro repetições, em parcelas subsubdivididas, alocando-se o fator cultivar na parcela e os fatores espaçamento entre plantas na subparcela e altura de desponta na sub-subparcela. Na safra 2007/08, os tratamentos consistiram na combinação de três espaçamentos entre plantas $(30,45$ e $60 \mathrm{~cm})$ e quatro alturas de desponta (sem desponta, cinco, sete e nove cachos por haste). O delineamento experimental foi blocos completos ao acaso, com quatro repetições, em parcelas subdivididas, alocando-se o fator espaçamento entre plantas na parcela e o fator altura de desponta na subparcela.
A cultivar utilizada na safra 2007/08 foi Takii 92. As sub-subparcelas na safra 2006/07 e as subparcelas na safra 2007/08 foram constituídas de uma linha de plantas com 6,0 m de comprimento e espaçamento entre linhas de 1,5 m.

Utilizou-se o sistema de plantio direto sobre a palhada da aveia preta, sem aplicação de herbicida. A adubação de base foi feita no sulco utilizando $80 \mathrm{~kg}$ $\mathrm{ha}^{-1}$ de $\mathrm{N}$ (nitrato de amônio), $320 \mathrm{~kg} \mathrm{ha}^{-1}$ de $\mathrm{P}_{2} \mathrm{O}_{5}$ (superfosfato triplo), $22 \mathrm{t} \mathrm{ha}^{-1} \mathrm{de}$ esterco de aves e 3,3 $\mathrm{kg} \mathrm{ha}^{-1}$ de B (bórax) na safra 2006/07. Na safra 2007/08 se utilizou $435 \mathrm{~kg} \mathrm{ha}^{-1}$ de $\mathrm{P}_{2} \mathrm{O}_{5}$ (superfosfato triplo), $7 \mathrm{t} \mathrm{ha}^{-1}$ de esterco de aves, $2,7 \mathrm{~kg} \mathrm{ha}^{-1}$ de B (bórax) e $8 \mathrm{~kg} \mathrm{ha}^{-1} \mathrm{de}$ $\mathrm{Zn}$ (sulfato de zinco). Os plantios foram realizados em 16/10/2006 e 21/11/2007. As despontas acima do $5^{\circ}, 7^{\circ}$ e $9^{\circ}$ cacho, de cada haste, foram realizadas, respectivamente, aos 86, 107 e 131 dias após o plantio (DAP) na safra 2006/2007, e aos 70,84 e 98 DAP na safra 2007/2008. As adubações de cobertura foram realizadas semanalmente a partir dos 21 DAP, totalizando $300 \mathrm{~kg} \mathrm{ha}^{-1}$ de $\mathrm{N}$ (nitrato de amônio) e $450 \mathrm{~kg} \mathrm{ha}^{-1}$ de $\mathrm{K}_{2} \mathrm{O}$ (cloreto de potássio) na safra 2006/2007, e 422 $\mathrm{kg} \mathrm{ha}^{-1}$ de $\mathrm{N}$ (nitrato de amônio) e $405 \mathrm{~kg}$ ha $^{-1}$ de $\mathrm{K}_{2} \mathrm{O}$ (cloreto de potássio) na safra $2007 / 2008$. As plantas foram conduzidas com duas hastes por planta no método de tutoramento vertical com fitilhos. As demais práticas culturais foram realizadas de acordo com as indicações técnicas para o tomateiro tutorado na região do Alto Vale do Rio do Peixe (Mueller et al., 2008).

Avaliou-se a produtividade total, comercial (extra AA e extra A) e descarte, a massa média de frutos comerciais (extra AA e extra A) e a porcentagem de frutos comerciais (extra AA e extra A) e descarte em relação ao número total de frutos. Foram considerados frutos extra AA com massa média maior que $150 \mathrm{~g}$ e frutos extra A com massa média entre 100 e $150 \mathrm{~g}$. Foram considerados como descarte os frutos com doenças fisiológicas ou fitopatológicas, frutos com ataque de insetos-praga e frutos miúdos (massa menor que $100 \mathrm{~g}$ ). As variáveis estudadas foram submetidas à análise de variância (teste F). Havendo significância estatística $(\mathrm{p} \leq 0,05)$, as médias foram comparadas pelo teste de
Tukey a 5\% de probabilidade de erro. As análises estatísticas foram realizadas através do pacote estatístico SISVAR versão 5.0 (Ferreira, 2000).

\section{RESULTADOS E DISCUSSÃO}

Não houve interação entre os fatores para todas as variáveis analisadas nas duas safras ( $p>0,05)$. Na safra 2006/07, a produtividade da cultivar Nemo Netta foi superior à da cultivar Débora Max em 7,9, 16,2 e 18,7\%, respectivamente para frutos total, extra A e descarte, não existindo diferenças quanto à produtividade de frutos nas classes comercial e extra AA (Tabela 1). A 'Nemo Netta' também apresentou massa média de frutos comercial, extra AA e extra A superior à 'Débora Max' em 17,5, 20,9 e 16,4\%, respectivamente (Tabela 2). Estes resultados estão de acordo com a avaliação de cultivares para o estado de Santa Catarina, 2006/07 (Epagri, 2006). Entretanto, a cultivar Débora Max apresentou maior porcentagem de frutos extra AA em relação à 'Nemo Netta' $(12,2 \%)$, não existindo diferenças entre as duas cultivares para porcentagem de frutos comerciais, miúdos, doentes e atacados por insetos-praga (Tabela 3).

Com relação ao espaçamento entre plantas, nas duas safras houve diferenças para a produtividade de frutos em todas as classes avaliadas, com exceção da produtividade de frutos extra AA (Tabela 1). O espaçamento de $30 \mathrm{~cm}$ entre plantas proporcionou as maiores produtividades de frutos total, comercial, extra A e descarte, não diferindo do espaçamento de $45 \mathrm{~cm}$ na safra 2007/08 para a produtividade de frutos total e comercial. O acréscimo na produtividade comercial de frutos com o menor espaçamento entre plantas, em relação ao espaçamento tradicional de $60 \mathrm{~cm}$, foi de 34,0 e $22,2 \%$ nas safras 2006/07 e 2007/08, respectivamente. Esses resultados são semelhantes aos encontrados por Streck et al. (1998), Carvalho \& Tessarioli Neto (2005), Seleguini et al. (2006) e Machado et al. (2007). Diferentemente dos resultados observados por Seleguini et al. (2002), a produtividade de frutos extra A aumentou com a redução do espaçamento entre plantas, porém, sem afetar 
Tabela 1. Produtividade de frutos total, comercial e descarte em função da cultivar, do espaçamento entre plantas e do número de cachos por haste (total, marketable and unmarketable yield as a function of cultivar, plant spacing and number of bunches per stem). Caçador, Epagri, 2006-2008.

\begin{tabular}{|c|c|c|c|c|c|c|c|c|c|c|}
\hline \multirow{3}{*}{ Fatores $^{1}$} & \multicolumn{10}{|c|}{$\begin{array}{l}\text { Produtividade de frutos }\left(\mathrm{t} \mathrm{ha}^{-1}\right) \\
\end{array}$} \\
\hline & \multicolumn{5}{|c|}{ Safra 2006/07 } & \multicolumn{5}{|c|}{ Safra $2007 / 08^{2}$} \\
\hline & Total & $\begin{array}{c}\text { Comer- } \\
\text { cial }\end{array}$ & $\begin{array}{c}\text { Extra } \\
\text { AA }\end{array}$ & $\begin{array}{c}\text { Extra } \\
\text { A }\end{array}$ & $\begin{array}{l}\text { Des- } \\
\text { carte }\end{array}$ & Total & $\begin{array}{c}\text { Comer- } \\
\text { cial }\end{array}$ & $\begin{array}{c}\text { Extra } \\
\text { AA }\end{array}$ & $\begin{array}{c}\text { Extra } \\
\text { A }\end{array}$ & $\begin{array}{l}\text { Des- } \\
\text { carte }\end{array}$ \\
\hline \multicolumn{11}{|l|}{ Cultivar } \\
\hline Débora Max & $105,0 \mathrm{~b}$ & $91,6 \mathrm{~ns}$ & $52,8 \mathrm{~ns}$ & $38,8 b$ & $13,4 b$ & - & - & - & - & - \\
\hline Nemo Netta & $113,3 \mathrm{a}$ & 97,3 & 52,3 & $45,1 \mathrm{a}$ & $15,9 \mathrm{a}$ & - & - & - & - & - \\
\hline \multicolumn{11}{|c|}{ Espaçamento entre plantas } \\
\hline 30 & $127,7 \mathrm{a}$ & $108,1 \mathrm{a}$ & $53,5 \mathrm{~ns}$ & $54,5 \mathrm{a}$ & $19,6 \mathrm{a}$ & $135,9 \mathrm{a}$ & $123,9 \mathrm{a}$ & $78,2 \mathrm{~ns}$ & $45,7 \mathrm{a}$ & $12,0 \mathrm{a}$ \\
\hline 45 & $108,4 \mathrm{~b}$ & $94,6 b$ & 55,0 & $39,6 b$ & $13,7 \mathrm{~b}$ & $124,1 \mathrm{a}$ & $116,8 \mathrm{a}$ & 84,6 & $32,2 b$ & $7,4 \mathrm{~b}$ \\
\hline 60 & $91,4 \mathrm{c}$ & $80,7 \mathrm{c}$ & 49,1 & $31,6 \mathrm{c}$ & $10,6 \mathrm{c}$ & $106,4 \mathrm{~b}$ & $101,4 \mathrm{~b}$ & 79,7 & $21,8 \mathrm{c}$ & $5,0 \mathrm{c}$ \\
\hline \multicolumn{11}{|c|}{$\begin{array}{l}\text { Altura de desponta } \\
\text { (número de cachos por haste) }\end{array}$} \\
\hline Cinco & $103,7 b$ & $91,4 \mathrm{~ns}$ & $53,2 \mathrm{~ns}$ & $38,2 b$ & $12,3 b$ & $123,4 \mathrm{~ns}$ & $115,3 \mathrm{~ns}$ & $84,0 \mathrm{ab}$ & $31,3 n s$ & $8,1 \mathrm{~ns}$ \\
\hline Sete & $109,9 \mathrm{ab}$ & 94,3 & 51,0 & $43,3 \mathrm{a}$ & $15,6 \mathrm{a}$ & 129,9 & 121,7 & $87,4 \mathrm{a}$ & 34,4 & 8,2 \\
\hline Nove & $112,2 \mathrm{a}$ & 96,7 & 54,5 & $42,2 \mathrm{a}$ & $15,5 \mathrm{a}$ & 117,7 & 109,1 & $75,4 \mathrm{~b}$ & 33,7 & 8,6 \\
\hline Sem desponta & $110,7 \mathrm{ab}$ & 95,5 & 51,4 & $44,0 \mathrm{a}$ & $15,2 \mathrm{a}$ & 117,6 & 110,0 & $76,5 \mathrm{ab}$ & 33,5 & 7,6 \\
\hline Média & 109,1 & 94,5 & 52,6 & 41,9 & 14,7 & 122,2 & 114,0 & 80,8 & 33,2 & 8,1 \\
\hline CV $1(\%)$ & 10,6 & 13,5 & 19,4 & 17,0 & 10,6 & 9,9 & 9,9 & 13,6 & 17,3 & 21,5 \\
\hline CV $2(\%)$ & 14,1 & 18,5 & 13,5 & 13,9 & 17,2 & 10,4 & 11,1 & 13,0 & 13,5 & 27,5 \\
\hline CV $3(\%)$ & 9,1 & 11,2 & 15,9 & 11,0 & 16,0 & - & - & - & - & - \\
\hline
\end{tabular}

${ }^{1}$ Médias seguidas pela mesma letra na coluna em cada variável analisada, dentro de cada fator, não diferem entre si pelo teste de Tukey $(\alpha=0,05) ;{ }^{2} \mathrm{Na}$ safra 2007/08 foi utilizada somente a cultivar Takii 92; ns Não houve diferenças significativas dentro do fator analisado pelo teste F (p>0,05). CV 1, CV 2 e CV 3 = coeficientes de variação para parcelas, subparcelas e sub-subparcelas, respectivamente $\left({ }^{1}\right.$ Means followed by the same letter in each evaluated variable, in each tested factor, did not differ through the Tukey test ( $\alpha=0,05) ;{ }^{2}$ In the $2007 / 08$ harvest only the cultivar Takii 92 was used; ${ }^{n}$ There was no difference in the analyzed factor, through the F test ( $\left.>>0,05\right)$; CV 1, CV 2 and CV 3 = coefficients of variation for plots, subplots and sub-subplots, respectively)

a produtividade de frutos extra $\mathrm{AA}$, de maior valor comercial (Tabela 1 ).

A massa média de frutos comercial, extra AA e extra A, em função da redução do espaçamento entre plantas, diminuiu somente no espaçamento de $30 \mathrm{~cm}$, com exceção da massa média comercial na safra 2007/08, que diminui a partir do espaçamento de $45 \mathrm{~cm}$ (Tabela 2). A redução da massa média de frutos comercial com o espaçamento entre plantas de $30 \mathrm{~cm}$, em relação ao espaçamento de $60 \mathrm{~cm}$, foi de 8,6 e 10,6\% para as safras de 2006/07 e 2007/08, respectivamente. Resultados semelhantes foram encontrados por Streck et al. (1998) e Machado et al. (2007). $\mathrm{O}$ adensamento das plantas aumenta a competição das plantas por luz (Streck et al., 1998). Desta forma, as plantas direcionam uma maior proporção de fotoassimilados para os processos de crescimento vegetativo, em detrimento ao crescimento dos frutos (Carvalho \& Tessarioli Neto, 2005).

Analisando a porcentagem de frutos em função do espaçamento entre plantas (Tabela 3), observa-se que houve diferença somente para frutos comerciais, extra AA e miúdos. A maior porcentagem de frutos comerciais foi obtida com o espaçamento de $60 \mathrm{~cm}$ entre plantas (tradicional), porém sem diferir do espaçamento de $45 \mathrm{~cm}$ nas duas safras. A redução da produção de frutos comerciais com o espaçamento de $30 \mathrm{~cm}$, em relação ao espaçamento de $60 \mathrm{~cm}$, foi de 6,7 e $7,7 \%$ para as safras de 2006/07 e 2007/08, respectivamente. A menor porcentagem de frutos comerciais com o espaçamento de $30 \mathrm{~cm}$ se deve à maior porcentagem de frutos miúdos, visto que não houve diferença entre espaçamentos para porcentagem de frutos doentes e atacados por insetos-praga. A pouca diferença encontrada para massa média de frutos comerciais (Tabela 2) e para porcentagem de frutos comerciais em relação ao total (Tabela 3) referenda os benefícios proporcionados pelo método de tutoramento vertical de plantas, principalmente em relação à melhor distribuição da radiação solar ao longo do dossel das plantas (Santos et al., 1999). Supõe-se que a penetração da radiação solar no dossel das plantas e, consequentemente, a atividade fotossintética das plantas possivelmente foram pouco afetadas pela redução do espaçamento de 60 para $45 \mathrm{~cm}$, contribuindo com uma boa disponibilidade de fotoassimilados para o crescimento dos frutos.

Em função dos níveis de desponta, houve diferença somente para produtividade total, extra A e descarte na safra 2006/07, e para produtividade extra AA na safra 2007/08 (Tabela 1). A produtividade de frutos comercial 
Tabela 2. Massa média de frutos comercial em função da cultivar, do espaçamento entre plantas e do número de cachos por haste (marketable fruit mean weight as a function of cultivar, plant spacing and number of bunches per stem). Caçador, Epagri, $2006-2008$.

\begin{tabular}{|c|c|c|c|c|c|c|}
\hline \multirow{3}{*}{ Fatores $^{1}$} & \multicolumn{6}{|c|}{ Massa média de fruto $(\mathrm{g})$} \\
\hline & \multicolumn{3}{|c|}{ Safra 2006/07 } & \multicolumn{3}{|c|}{ Safra $2007 / 08^{2}$} \\
\hline & Comercial & Extra AA & Extra A & Comercial & Extra AA & Extra A \\
\hline \multicolumn{7}{|l|}{ Cultivar } \\
\hline Débora Max & $131,6 b$ & $150,0 \mathrm{~b}$ & $112,5 b$ & - & - & - \\
\hline Nemo Netta & $154,6 \mathrm{a}$ & $181,4 \mathrm{a}$ & $130,9 \mathrm{a}$ & - & - & - \\
\hline \multicolumn{7}{|c|}{ Espaçamento entre plantas } \\
\hline 30 & $135,8 b$ & $159,5 b$ & $118,9 b$ & $160,3 \mathrm{c}$ & $183,9 b$ & $131,9 b$ \\
\hline 45 & $144,7 \mathrm{a}$ & $167,1 \mathrm{a}$ & $122,2 \mathrm{a}$ & $170,9 b$ & $190,7 \mathrm{a}$ & $134,9 \mathrm{a}$ \\
\hline 60 & $148,5 \mathrm{a}$ & $170,6 \mathrm{a}$ & $123,8 \mathrm{a}$ & $179,4 \mathrm{a}$ & $196,5 \mathrm{a}$ & $135,8 \mathrm{a}$ \\
\hline \multicolumn{7}{|c|}{$\begin{array}{l}\text { Altura de desponta } \\
\text { (número de cachos por haste) }\end{array}$} \\
\hline Cinco & $144,9 a$ & $167,1 \mathrm{~ns}$ & $121,8 \mathrm{~ns}$ & $172,2 \mathrm{a}$ & $192,2 \mathrm{a}$ & $133,2 \mathrm{~ns}$ \\
\hline Sete & $141,3 b$ & 165,4 & 120,4 & $172,1 \mathrm{a}$ & $191,8 \mathrm{a}$ & 135,6 \\
\hline Nove & $144,1 \mathrm{ab}$ & 165,9 & 122,7 & $167,2 b$ & $188,2 \mathrm{~b}$ & 133,4 \\
\hline Sem desponta & $141,7 \mathrm{ab}$ & 164,5 & 121,8 & $169,3 \mathrm{ab}$ & $189,2 \mathrm{ab}$ & 134,4 \\
\hline Média & 143,0 & 165,7 & 121,7 & 170,2 & 190,4 & 134,2 \\
\hline CV $1(\%)$ & 4,8 & 3,0 & 5,6 & 4,5 & 3,2 & 1,3 \\
\hline CV $2(\%)$ & 3,8 & 4,4 & 2,6 & 2,0 & 1,5 & 1,7 \\
\hline CV $3(\%)$ & 3,5 & 2,8 & 3,4 & - & - & - \\
\hline
\end{tabular}

${ }^{1}$ Médias seguidas pela mesma letra na coluna, dentro de cada fator, não diferem entre si pelo teste de Tukey $(\alpha=0,05) ;{ }^{2} \mathrm{Na}$ safra $2007 / 2008$ foi utilizada somente a cultivar Takii 92. ${ }^{\text {ns }}$ Diferenças não-significativas a 5\% de probabilidade de erro; CV 1 , CV 2 e CV $3=$ coeficientes de variação para parcelas, subparcelas e sub-subparcelas, respectivamente ( ${ }^{1}$ Means followed by the same letter in each evaluated variable, in each tested factor, did not differ through the Tukey test $(\alpha=0,05) ;{ }^{2}$ In the 2007/08 harvest only the cultivar Takii 92 was used; ${ }^{\text {ns }}$ There was no difference in the analyzed factor, through the F test $(\mathrm{p}>0,05)$. CV 1, CV 2 and CV $3=$ coefficients of variation for plots, subplots and sub-subplots, respectively).

não diferiu entre as alturas de desponta testadas. Estes resultados são diferentes dos obtidos por Seleguini et al. (2006) e Machado et al. (2007), que observaram redução da produtividade de frutos com a diminuição do número de cachos por planta. Entretanto, o número de cachos por planta testados por estes autores foram menores que os do presente experimento. A possibilidade de desponta acima do $5^{\circ}$ cacho de cada haste, sem haver perdas na produtividade comercial de frutos, traz uma série de benefícios para a cultura e para o produtor. Segundo Seleguini et al. (2006), a diminuição do número de cachos por planta reduz o ciclo da cultura e a altura de plantas, proporcionando menor utilização de mão-de-obra durante o ciclo da cultura e menor uso de defensivos agrícolas. Além disso, a menor altura das plantas permite uma maior eficiência no controle de pragas e doenças e melhor distribuição de luz na cultura (Selegui- ni et al., 2006). A redução do ciclo da cultura, através da desponta, pode ser utilizada como um mecanismo de escape contra a incidência de doenças (Streck et al., 1998).

Houve diferença, em função da altura de desponta, somente para massa média de frutos para a classe comercial na safra 2006/07 e para as classes comercial e extra AA na safra 2007/08 (Tabela 2). Na safra 2006/07, a maior massa média na classe comercial foi observada com cinco cachos por haste, não diferindo de nove cachos por haste e do tratamento sem desponta. Na safra 2007/08, a maior massa média de frutos nas classes comercial e extra AA foi observada com cinco e sete cachos por haste, não diferindo do tratamento sem desponta. Esses resultados diferem dos observados por Machado et al. (2007), em que a redução do número de cachos por planta aumentou a massa média de frutos. Entretanto, para as maiores alturas de desponta avaliadas no presente experimento, muitos dos frutos localizados nos cachos superiores não atingiram o ponto de colheita ao final da safra. Estes frutos foram eliminados com a parte vegetativa, conforme também observado por Streck et al. (1998) e, por possuírem menor tamanho (Oliveira et al., 1995), acabam não contribuindo com a diminuição da massa média de frutos nos tratamentos com maior altura de desponta ou sem a realização da desponta.

Houve diferença para a porcentagem de frutos em relação ao total para as classes comercial, extra AA e miúdo na safra 2006/07. A desponta realizada acima do $5^{\circ}$ cacho de cada haste proporcionou maior porcentagem de frutos comercial e extra AA e menor porcentagem de frutos miúdos na safra 2006/07.

De acordo com os resultados alcançados, a redução do espaçamento entre 
Tabela 3. Número de frutos comercial, extra AA, miúdos, doentes e atacados por insetos-praga em relação ao número total de frutos, em função da cultivar, do espaçamento entre plantas e do número de cachos por haste (marketable and unmarketable number of fruits in relation to the total number of fruits as a function of cultivar, plant spacing and number of bunches per stem). Caçador, Epagri, $2006-2008$.

\begin{tabular}{|c|c|c|c|c|c|c|c|c|c|c|}
\hline \multirow{3}{*}{ Fatores ${ }^{1}$} & \multicolumn{10}{|c|}{ Número de frutos em relação ao total (\%) } \\
\hline & \multicolumn{5}{|c|}{ Safra 2006/07 } & \multicolumn{5}{|c|}{$\begin{array}{l}\text { Safra } 2007 / 08^{2} \\
\end{array}$} \\
\hline & $\begin{array}{c}\text { Comer- } \\
\text { cial }\end{array}$ & $\begin{array}{c}\text { Extra } \\
\text { AA }\end{array}$ & Miúdo & Doente & Inseto & $\begin{array}{c}\text { Comer- } \\
\text { cial }\end{array}$ & $\begin{array}{c}\text { Extra } \\
\text { AA }\end{array}$ & Miúdo & Doente & Inseto \\
\hline \multicolumn{11}{|l|}{ Cultivar } \\
\hline Débora Max & $79,5 \mathrm{~ns}$ & $40,5 \mathrm{a}$ & $16,9 \mathrm{~ns}$ & $1,3 \mathrm{~ns}$ & $2,3 \mathrm{~ns}$ & - & - & - & - & - \\
\hline Nemo Netta & 77,7 & $36,1 b$ & 18,3 & 1,9 & 2,1 & - & - & - & - & - \\
\hline \multicolumn{11}{|c|}{ Espaçamento entre plantas } \\
\hline 30 & $75,6 \mathrm{~b}$ & $32,0 b$ & $20,9 a$ & $1,4 \mathrm{~ns}$ & $2,1 \mathrm{~ns}$ & $85,4 b$ & $47,0 \mathrm{c}$ & $11,0 \mathrm{a}$ & $1,9 \mathrm{~ns}$ & $1,6 \mathrm{~ns}$ \\
\hline 45 & $79,4 \mathrm{ab}$ & $40,0 \mathrm{a}$ & $16,9 \mathrm{ab}$ & 1,6 & 2,1 & $90,3 \mathrm{a}$ & $58,8 \mathrm{~b}$ & $6,4 b$ & 1,8 & 1,5 \\
\hline 60 & $81,0 \mathrm{a}$ & $43,0 \mathrm{a}$ & $14,9 \mathrm{~b}$ & 1,7 & 2,4 & $92,5 \mathrm{a}$ & $66,4 \mathrm{a}$ & $4,4 b$ & 1,9 & 1,3 \\
\hline
\end{tabular}

Altura de desponta

(número de cachos por haste)

\begin{tabular}{|c|c|c|c|c|c|c|c|c|c|c|}
\hline Cinco & $81,3 \mathrm{a}$ & $41,7 \mathrm{a}$ & $14,5 b$ & $1,7 \mathrm{~ns}$ & $2,5 \mathrm{~ns}$ & $89,2 \mathrm{~ns}$ & $58,6 \mathrm{~ns}$ & $7,7 \mathrm{~ns}$ & $1,8 \mathrm{~ns}$ & $1,3 \mathrm{~ns}$ \\
\hline Sete & $77,1 \mathrm{~b}$ & $35,9 b$ & $19,1 \mathrm{a}$ & 1,8 & 2,0 & 90,2 & 58,9 & 6,3 & 2,1 & 1,4 \\
\hline Nove & $78,4 \mathrm{ab}$ & $38,9 \mathrm{ab}$ & $17,8 \mathrm{ab}$ & 1,6 & 2,2 & 88,3 & 54,9 & 8,5 & 1,7 & 1,5 \\
\hline Sem desponta & $77,8 \mathrm{ab}$ & $36,7 b$ & $18,8 \mathrm{a}$ & 1,3 & 2,1 & 89,9 & 57,1 & 6,6 & 1,9 & 1,6 \\
\hline Média & 78,6 & 38,3 & 17,6 & 1,6 & 2,2 & 89,4 & 57,4 & 7,3 & 1,9 & 1,4 \\
\hline CV $1(\%)$ & 7,3 & 14,4 & 33,6 & 59,5 & 58,7 & 3,0 & 9,8 & 42,1 & 26,7 & 45,4 \\
\hline CV $2(\%)$ & 8,6 & 12,8 & 35,7 & 44,1 & 38,4 & 4,0 & 8,9 & 47,0 & 32,0 & 55,8 \\
\hline CV $3(\%)$ & 5,9 & 13,1 & 26,0 & 53,0 & 38,8 & - & - & - & - & - \\
\hline
\end{tabular}

${ }^{1}$ Médias seguidas pela mesma letra na coluna, dentro de cada fator, não diferem entre si pelo teste de Tukey $(\alpha=0,05) .{ }^{2}$ na safra $2007 / 2008$ foi utilizada somente a cultivar Takii 92; ns Diferenças não-significativas a 5\% de probabilidade de erro; CV 1, CV 2 e CV 3 = coeficientes de variação para parcelas, subparcelas e sub-subparcelas, respectivamente ( ${ }^{1}$ Means followed by the same letter in each evaluated variable, in each tested factor, did not differ through the Tukey test $(\alpha=0,05) ;{ }^{2}$ In the 2007/08 harvest only the cultivar Takii 92 was used; ${ }^{\text {ns }}$ There was no difference in the analyzed factor, through the F test ( $>00,05)$. CV 1, CV 2 and CV 3 = coefficients of variation for plots, subplots and sub-subplots, respectively).

plantas de 60 para $45 \mathrm{~cm}$, no tutoramento vertical com fitilhos, aumenta a produtividade de frutos comerciais sem comprometer a qualidade dos frutos. $\mathrm{O}$ tomateiro pode ser conduzido com cinco cachos por haste sem comprometer a produtividade de frutos comerciais, no tutoramento vertical com fitilhos.

\section{AGRADECIMENTOS}

Os autores agradecem ao MAPA/ CNPq, pelo financiamento parcial dos experimentos através do projeto Produção Integrada de Tomate de Mesa de Santa Catarina, e às empresas Agrocinco/Nirit Seeds Ltda, Sakata Seed Sudamérica Ltda e Sementes Takii, pelo apoio na implantação dos experimentos.

\section{REFERÊNCIAS}

BOFF P; FONTES PCR; VALE FX; ZAMBOLIM L. 1992. Controle da mancha de estenfílio e da pinta-preta do tomateiro em função do sistema de condução. Horticultura brasileira 10: 25-27.

CARVALHO LA; TESSARIOLI NETO J. 2005. Produtividade de tomate em ambiente protegido, em função do espaçamento e número de ramos por planta. Horticultura Brasileira 23: 986-989.

EMBRAPA. 1999. Centro Nacional de Pesquisas de Solos. Sistema brasileiro de classificação de solos. Brasília: EMBRAPA. 412p.

EPAGRI. 2006. Avaliação de cultivares para o Estado de Santa Catarina 2006/2007. Florianópolis: Epagri. 162p. (EPAGRI. Boletim Técnico, 128).

FERREIRA DF. 2000. Análises estatísticas por meio do Sisvar para Windows versão 4.0. In... REUNIÃO ANUAL DA REGIÃO BRASILEIRA DA SOCIEDADE INTERNACIONAL DE BIOMETRIA, 45. Anais... São Carlos: UFSCar. p.255-258.

MACHADO AQ; ALVARENGA MAR.; FLORENTINO CET. 2007. Produção de tomate italiano (saladete) sob diferentes densidades de plantio e sistemas de poda visando ao consumo in natura. Horticultura Brasileira 25: 149-153.

MUELLER S; WAMSER AF; BECKER WF; SANTOS JP. 2008. Indicações técnicas para o tomateiro tutorado na região do Alto Vale do Rio do Peixe. Florianópolis: Epagri. 78p. (Epagri. Sistemas de Produção, 45).

OLIVEIRA VR; CAMPOS JP; FONTES PCR; REIS FP. 1995. Efeito do número de hastes por planta e poda apical na produção classificada de frutos de tomateiro (Lycopersicon esculentum MILL.). Ciência e Prática 19: 414-419.

PEREIRA C; MARCHI G; SILVA EC. 1999. Produção de tomate-caqui em estufa. Lavras: UFLA. 26p. (UFLA. Boletim técnico. Série extensão).

PICANÇO M; GUEDES RNC; LEITE GLD; FONTES PCR; SILVA EA. 1995. Incidência de Scrobipalpuloides absoluta em tomateiro sob diferentes sistemas de tutoramento e de controle químico. Horticultura brasileira 13: $180-183$.

REBELO JA. 1993. Sistema alternativo de tutoramento para tomateiro. Horticultura Brasileira 11: 161.

SANTOS HS; PERIN WH; TITATO LG; VIDA JB; CALLEGARI O. 1999. Avaliação de sistemas de condução em relação à severidade 
de doenças e à produtividade do tomate. Acta Scientiarum 21: 453-457.

SELEGUINI A; SENO S; FARIA JÚNIOR MJA. 2006. Espaçamento entre plantas e número de racimos para tomateiro em ambiente protegido. Acta Scientiarum. Agronomy 28: 359-363.

SELEGUINI A; SENO S; ZIZAS GB. 2002. Influência do espaçamento entre plantas e número de cachos por planta na cultura do tomateiro, em condições de ambiente protegido. In: CONGRESSO BRASILEIRO DE OLERICULTURA, 42. Resumos... Uberlândia: SOB. (CD-ROM).

STRECK NA; BURIOL GA; ANDRIOLO JL; SANDRI MA. 1998. Influência da densidade de plantas e poda apical drástica na produtividade do tomateiro em estufa de plástico. Pesquisa Agropecuária Brasileira 33: 1105-1112.

WAMSER AF; BECKER WF; SANTOS JP;
MUELLER S. 2008. Influência do sistema de condução do tomateiro sobre a incidência de doenças e insetos-praga. Horticultura Brasileira 26: 180-185.

WAMSER AF; MUELLER S; BECKER WF; SANTOS JP. 2007. Produção do tomateiro em função dos sistemas de condução de plantas. Horticultura Brasileira 25: 238-243. 